\title{
Laparoscopic Management of Median Arcuate Ligament Syndrome: Single Center Experience
}

\author{
Eppa Vimalakar Reddy ${ }^{1}$, Gourang Shroff ${ }^{2}$, Vemula Bala Reddy ${ }^{3}$, Akella V Phanendra Somayajulu ${ }^{4}$
}

\begin{abstract}
Median arcuate ligament syndrome (MALS) is a rare disease caused as a result of extrinsic compression by diaphragmatic fibers arching on the celiac artery at its point of origin from the abdominal aorta. Patients suffering from MALS presented with weight loss, nausea, vomiting, and postprandial epigastric pain. Often misdiagnosed with dyspepsia or acid peptic disease, this syndrome is a diagnosis by exclusion, after excluding commoner causes of the upper abdomen pain. It is diagnosed with computed tomographic (CT) angiography and treated with various modalities, including laparoscopic or open division of fibers of MAL, which cause extrinsic pressure. We report a series of three cases of MALS diagnosed and managed at our center, using laparoscopic division of the fibers and release of the celiac artery.

Keywords: Celiac artery compression syndrome, Dunbar syndrome, Laparoscopy, Median arcuate ligament syndrome, Minimal invasive. World Journal of Laparoscopic Surgery (2019): 10.5005/jp-journals-10033-1358
\end{abstract}

\section{INTRODUCTION}

The median arcuate ligament (MAL) is an arch of diaphragmatic fibers crossing the aorta, superior to the celiac artery origin and at the level of diaphragmatic insertion. ${ }^{1-3}$ Its lower insertion crosses the proximal part of the celiac artery. ${ }^{1-5}$

MALS is a rare disease caused by the extrinsic compression on the celiac artery by inferior insertion of the median arcuate ligament fibers (Fig. 1). ${ }^{1-5}$ This leads to ischemia to the bowel supplied by the celiac artery. It is also known as celiac artery compression syndrome (CACS) or dunbar syndrome.

An estimated $10-24 \%$ of people may have indentation of celiac artery caused by an abnormally low placed ligament. ${ }^{6}$ But only a minor fraction will have a clinically significant disease.

The clinical presentation of celiac artery compression include weight loss, nausea, vomiting, and abdominal pain, which are particularly aggravated after a meal. ${ }^{3-5}$ The condition may sometimes present atypically with exercise-related abdominal pain/diarrhea ${ }^{12}$ (more in athletes), or rupture of a pancreaticoduodenal artery pseudo-aneurysm (due to post-stenotic dilatation of celiac trunk). ${ }^{7,8}$

MALS is a diagnosis of exclusion. A strong clinical suspicion is required in making the diagnosis of this syndrome. The diagnosis of significant celiac axis compression was previously made with conventional angiography. However now, it can be very well diagnosed with the three-dimensional computed tomographic (CT) angiography. ${ }^{2}$ Convensional angiography/plasty of the celiac artery is now only used either as a primary treatment modality 9,10 or for postoperative stenosis. ${ }^{11}$

The primary treatment options for management of this syndrome are either open or laparoscopic division of fibers of MAL, or angiographic stenting of the celiac artery in resistant cases. Robotic surgery has also been projected as a treatment option in recent days.

\section{Materials and Methods}

We report a case series of three cases of MALS diagnosed and managed with the laparoscopic approach at our center.

\footnotetext{
${ }^{1-4}$ Department of Surgical Gastroenterology, Sunshine Hospitals, Secunderabad, Telangana, India

Corresponding Author: Eppa Vimalakar Reddy, Department of Surgical Gastroenterology, Sunshine Hospitals, Secunderabad, Telangana, India, Phone: +91 9573201103, e-mail: vimalakarreddy@ gmail.com

How to cite this article: Reddy EV, Shroff G, Reddy VB, et al. Laparoscopic Management of Median Arcuate Ligament Syndrome: Single Center Experience. World J Lap Surg 2019;12(1):39-42.

Source of support: Nil

Conflict of interest: None
}

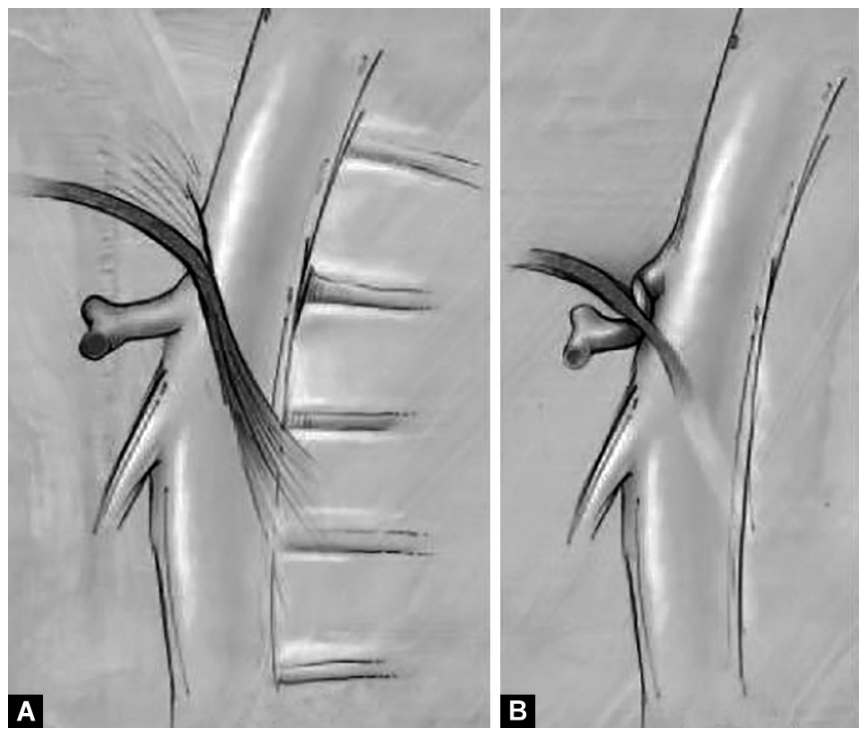

Figs $1 \mathrm{~A}$ and $\mathrm{B}$ : (A) Normal anatomy of ligament crossing anterior to aorta; (B) In MALS, it crosses the proximal portion of the celiac trunk, causing indentation

(0) The Author(s). 2019 Open Access This article is distributed under the terms of the Creative Commons Attribution 4.0 International License (https://creativecommons. org/licenses/by-nc/4.0/), which permits unrestricted use, distribution, and non-commercial reproduction in any medium, provided you give appropriate credit to the original author(s) and the source, provide a link to the Creative Commons license, and indicate if changes were made. The Creative Commons Public Domain Dedication waiver (http://creativecommons.org/publicdomain/zero/1.0/) applies to the data made available in this article, unless otherwise stated. 


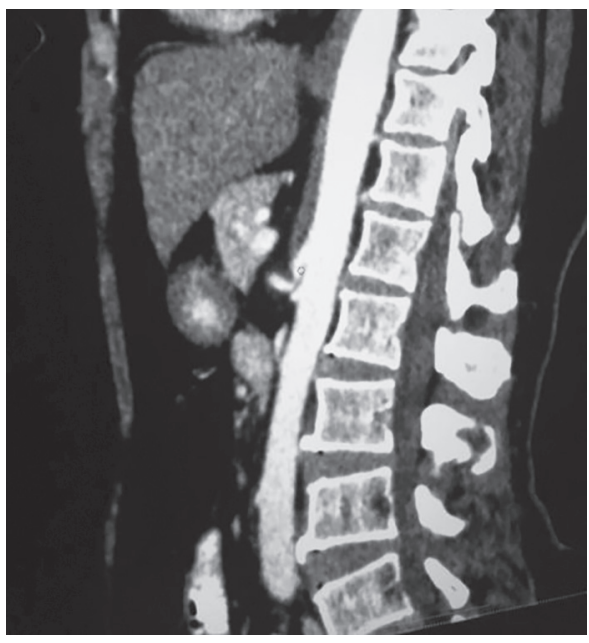

Fig. 2: A CT angiography image of the patient (sagittal view) showing compression of the celiac trunk with post stenotic dilatation

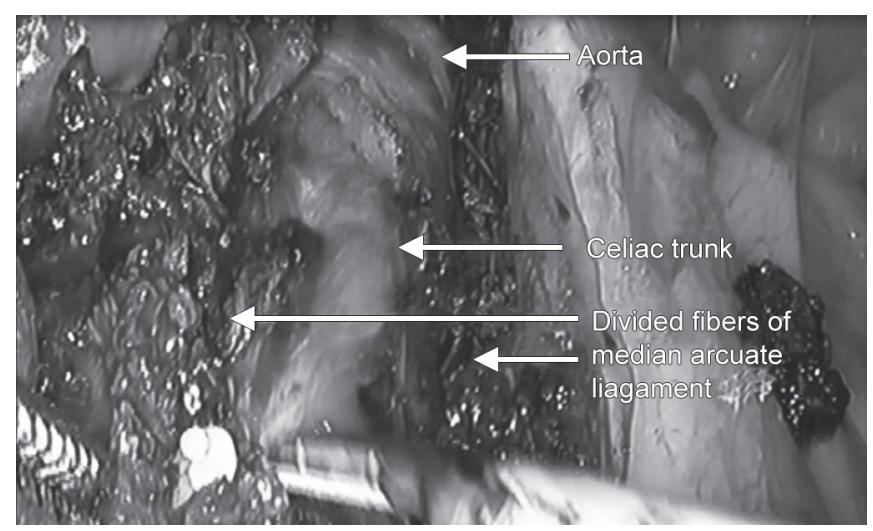

Fig. 4: An intraoperative image of the celiac trunk after division of the fibers of median arcuate ligament

\section{Surgical Technique Employed}

The patient is placed in a supine position with leg split and in a head-up position. The aorta and diaphragmatic arches identified and dissected until the origin of celiac artery. Any external compression on the artery is released and the artery is completely skeletonized.

\section{Case Description}

\section{Case 1}

A 52-year-old gentleman came with the complaints of severe postprandial abdominal pain for 6 months, a history of vomiting since 1 month and a history of approx $15 \mathrm{~kg}$ loss of weight in last 6 months.

Upper GI endoscopy shows grosive gastropathy and colonoscopy was normal. CT angiography of the abdomen showed a high-grade stenosis at the origin of the celiac trunk without any significant intraluminal plaque or calcification (Figs 2 and 3).

After trial of conservative management for erosive gastropathy, as the patient was refractory, diagnosis of MALS was made and taken up for surgery.

Postoperatively, liquids were started on 2nd POD, a soft diet on 4th POD, and then the patient was discharged. On a serial followup

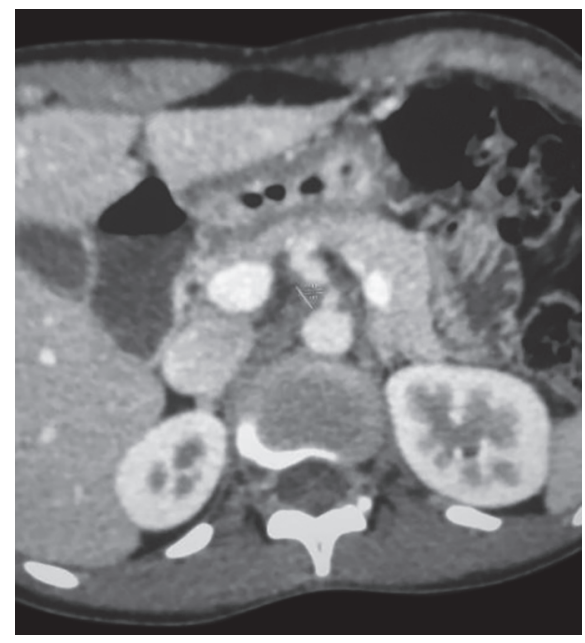

Fig. 3: A CT angiography image (axial view) showing compression of the celiac trunk with post stenotic dilatation

up to 2 years, the patient is significantly pain free, tolerating the diet well.

\section{Case 2}

A 22-year-old lady came with chief complaints of severe epigastric abdominal pain aggravated for 5 days, with a history of similar complaints for the last 2 years, and moderate severity aggravated by food intake. A history of nausea was present on and off. No history of vomiting or fever was found to be associated with the symptoms. A history of approx $10 \mathrm{~kg}$ loss of weight was present in the last 6 months.

Upper Gl endoscopy and colonoscopy normal. CECT abdomen revealed significant compression on the proximal part of the celiac artery by median arcuate ligament-suggestive of MALS.

The patient underwent laparoscopic release of median arcuate ligament impingement on the celiac artery (Fig. 4).

Postoperatively, liquids were started on 2nd POD, a soft diet on 4th POD, and then the patient was discharged. On serial follow-up up to 1 year, the patient's post prandial abdominal pain has significantly resolved. She is tolerating oral diet well.

\section{Case 3}

A 44-year-old female with chief complaints of severe pain abdomen with anxiety and insomnia since 6 months. No history of vomiting or nausea. History of approx. $12 \mathrm{~kg}$ weight loss in the last 6 months.

Upper GI endoscopy and colonoscopy were normal. CECT abdomen revealed significant compression of the proximal part of the celiac artery by fibers from diaphragmatic crura-suggestive of MALS.

The patient underwent laparoscopic release of the fibers causing compression. Postoperative liquids were started on 1st POD, a soft diet on 3rd POD, and then the patient was discharged. On serial follow-up upto 9 months, the patient was significantly asymptomatic.

\section{Results}

In this study, three patients were evaluated, diagnosed, and treated by laparoscopic division of diaphragmatic fibers.

Two of the three were females. The mean age at presentation was 39.3 years (22-52). All 3 patients presented with upper 
abdominal pain, which was not responding to conventional PPI therapy. The mean weight loss of $12.33 \mathrm{~kg}$ was reported $(10-15 \mathrm{~kg})$. The length of symptoms at presentation was a mean of 12 months (6-24).

On evaluation with CT angiography, all 3 revealed significant compression of the celiac trunk at its origin from aorta. All three patients underwent laparoscopic division of MAL fibers. None of the patients required conversions to open.

The length of the postoperative stay ranged from 3 to 4 days, with all patients being discharged with no postoperative complications or morbidity. On average, followup of 15 months (9-24) showed that all three patients remained symptom free and tolerated diet well.

\section{Discussion}

Since the first description of MALS in 1961, there are several debates on the diagnosis and treatment of this rare clinical entity.

The mean age of presentation in our study is around 39.3 years, which correlates with the literature quoted age of 47 years. ${ }^{4}$ However, many studies quote a younger age of presentation, around 2nd or 3rd decade of life. Two of the three patients were females, in accordance with most cited literature mentioning more prevalence among female population.

Our study demonstrates successful management of MALS with a multidisciplinary approach. This condition is diagnosed mostly on initial duplex ultrasound imaging followed by UGI endoscopy and contrast CT angiography of the abdomen and is managed with laparoscopic division of median arcuate ligament fibers.

Selecting patients for laparoscopic treatment of MALS is a clinical challenge. Most cases are misdiagnosed and managed for a long time with PPIs and other supportive treatment. Diagnosis of MALS requires a high degree of clinical suspicion along with appropriate investigative workup. It is further complicated owing to a high prevalence of asymptomatic anatomic compression of celiac artery on CT overlapped with pain abdomen. Hence, probably, the diagnosis of MALS can only be confirmed postoperatively if the patient is significantly relieved of the symptoms after release of MAL fibers.

Once the diagnosis of MALS is made, the next challenge is to select the approach to divide the MAL fibers. Various methods have been proposed, including open approach, laparoscopic, robotic, and retroperitoneal endoscopic. Van Petersen et al. ${ }^{21}$ demonstrated a retroperitoneal endoscopic MAL release and Relles et al. ${ }^{22}$ reported a robotic-assisted MAL release technique. A minimally invasive approach has obvious advantages in this group of relatively young cohort. Laparoscopic approach has gained significant popularity over time, surpassing open approach in most cases, as an initial treatment approach.

We, at our center, recommend laparoscopic management owing to the basic advantages of minimal invasive approach clubbed with acceptable learning curve and ease along with excellent visualization of the celiac trunk origin and the MAL. In our study, a laparoscopic approach was associated with no perioperative morbidity, a short hospital stay, and minimal blood loss, with acceptable results and patient satisfaction, consistent with other reports. ${ }^{13-20}$ Patients were followed up at 1 month and then every 3 months till 2 years. All the patients were asymptomatic at follow-up.
Despite the acceptable satisfaction rates, a subset of MALS patients may remain refractory with partial or no relief of symptoms or may have recurrent symptoms, requiring further intervention like angioplasty or stenting.

Limitations of our study is the small number of cases, owing to rarity of the disease.

\section{Conclusion}

MALS is a rare clinical disease, requiring high clinical suspicion for diagnosis. Management includes surgical division of MAL fibers. Laparoscopic management is gaining popularity and recommended owing to the basic advantages of minimal invasive approach clubbed with acceptable learning curve and ease of performing, along with excellent visualization of the celiac trunk origin and the MAL.

\section{References}

1. Horton KM, Talamini MA, et al. Median arcuate ligament syndrome: evaluation with CT angiography. Radiographics 2005;25:1177-1182. DOI: 10.1148/rg.255055001.

2. Kopecky KK, Stine SB, et al. Median arcuate ligament syndrome with multivessel involvement: diagnosis with spiral CT angiography. Abdom Imaging 1997;22:318-320. DOI: 10.1007/s002619900199.

3. Taylor Jr LM, Moneta GL. Management of visceral ischemic syndromes. In: Rutherford RB. ed. Vascular Surgery. Philadelphia:WB Saunders; 2000. pp. 1501-1511.

4. Reilly LM, Ammar AD, et al. Late results following operative repair for celiac artery compression syndrome. J Vasc Surg 1985;2:79-91. DOI: 10.1016/0741-5214(85)90177-6.

5. Takach TJ, Livesay JJ, et al. Celiac compression syndrome: tailored therapy based on intraoperative findings. J Am Coll Surg 1996;183:606-610.

6. Duffy AJ, Panait $L$, et al. Management of median arcuate ligament syndrome: a new paradigm. Ann Vasc Surg 2009 Nov-Dec;23(6): 778-784. DOI: 10.1016/j.avsg.2008.11.005.

7. Akatsu T, Hayashi $S$, et al. Emergency embolization of a ruptured pancreaticoduodenal artery aneurysm associated with the median arcuate ligament syndrome. J Gastroenterol Hepatol 2004;19: 482-483. DOI: 10.1111/j.1440-1746.2004.03385.x.

8. Habre J, Bernard JL, et al. Rupture of a pancreaticoduodenal artery aneurysm with median arcuate ligament syndrome: report of a case [in French]. Ann Chir 2005;130:178-180. DOI: 10.1016/ j.anchir.2004.12.019.

9. Matsumoto $\mathrm{AH}$, Tegtmeyer $\mathrm{CJ}$, et al. Percutaneous transluminal angioplasty of visceral arterial stenoses: results and long-term clinical follow-up. J Vasc Interv Radiol 1995;6:165-174. DOI: 10.1016/S10510443(95)71087-9.

10. Cinà CS, Safar H. Successful treatment of recurrent celiac axis compression syndrome. A case report. Panminerva Med 2002;44: 69-72.

11. Saddekni S, Sniderman KW, et al. Percutaneous transluminal angioplasty of nonatherosclerotic lesions. Am J Roentgenol 1980;135:975-982. DOI: 10.2214/ajr.135.5.975.

12. Desmond CP, Roberts SK. Exercise-related abdominal pain as a manifestation of the median arcuate ligament syndrome. Scand J Gastroenterol 2004;39:1310-1313. DOI: 10.1080/00365520410008150.

13. Jimenez JC, Harlander-Locke M, et al. Open and laparoscopic treatment of median arcuate ligament syndrome. J Vasc Surg 2012;56:869-873. DOI: 10.1016/j.jvs.2012.04.057.

14. Roseborough GS. Laparoscopic management of celiac artery compression syndrome. J Vasc Surg 2009;50:124-133. DOI: 10.1016/ j.jvs.2008.12.078. 
15. Vaziri K, Hungness ES, et al. Laparoscopic treatment of celiac artery compression syndrome: case series and review of current treatment modalities. J Gastrointest Surg 2009;13:293-298. DOI: 10.1007/s11605008-0702-9.

16. El-Hayek KM, Titus J, et al. Laparoscopic median arcuate ligament release: are we improving symptoms? J Am Coll Surg 2013;216: 272-279. DOI: 10.1016/j.jamcollsurg.2012.10.004.

17. Berard X, Cau J, et al. Laparoscopic surgery for coeliac artery compression syndrome: current management and technical aspects. Eur J Vasc Endovasc Surg 2012;43:38-42. DOI: 10.1016/ j.ejvs.2011.09.023.

18. Baccari $\mathrm{P}$, Civilini $\mathrm{E}$, et al. Celiac artery compression syndrome managed by laparoscopy. J Vasc Surg 2009;50:134-139. DOI: 10.1016/ j.jvs.2008.11.124.
19. Tulloch AW, Jimenez JC, et al. Laparoscopic vs open celiac ganglionectomy in patients with median arcuate ligament syndrome. J Vasc Surg 2010;52:1283-1289. DOI: 10.1016/j.jvs.2010. 05.083.

20. Mak GZ, Speaker $C$, et al. Median arcuate ligament syndrome in the pediatric population. J Pediatr Surg 2013;48:2261-2270. DOI: 10.1016/ j.jpedsurg.2013.03.003.

21. Van Petersen AS, Vriens BH, et al. Retroperitoneal endoscopic release in the management of celiac artery compression syndrome. J Vasc Surg 2009;50:140-147. DOI: 10.1016/j.jvs. 2008.12.077.

22. Moudgill N, Relles D, et al. Robotic-Assisted Treatment of Median Arcuate Ligament Syndrome. J Vasc Surg 2011;54(3):918-919. DOI: 10.1016/j.jvs.2011.06.044. 